\title{
Effects of $\mathrm{Na}_{2} \mathrm{O} / \mathrm{K}_{2} \mathrm{O}$ Ratio on the Deformation Behaviour of the Floor Tile Bodies
}

\author{
N. Tamsu, A. Vedat Bayrak and H. Ozdemir \\ Eczacibasi Building Products Co., Innovation Center Bozuyuk/Bilecik, Turkey
}

\begin{abstract}
Floor tile bodies have excellent technical characteristics particularly as regards mechanical properties and frost resistance. Besides of these properties they could not have any deformation during firing. Considering floor tiles are generally fired in roller kilns, tiles are moving along the kiln carried by the rollers. It is possible that tiles can be bended by the roller movement because it is submitted to vertical forces due to its own weight. Pyroplastic deformation is the bending of a ceramic specimen caused by gravity during heat treatment. It can be defined as deformation or the loss of a shape of a product during its firing. Deformation behaviour of the tiles is related to liquid phases formed during firing or to a reduced viscosity of these phases. In this study, effects of altering $\mathrm{SiO}_{2} / \mathrm{Al}_{2} \mathrm{O}_{3}$ ratio and $\mathrm{Na}_{2} \mathrm{O} / \mathrm{K}_{2} \mathrm{O}$ ratio of the tile composition on the deformation behaviour of the floor tiles. Correlations between compositional change and deformation behaviour of the tile bodies will be also discussed in this presentation.
\end{abstract}

DOI: 10.12693/APhysPolA.123.283

PACS: 81.05.Mh

\section{Introduction}

Floor tile bodies are ceramic building material with high bending strength and abrasion resistance. Recently, it has experienced the increase in production and sales of all ceramic building materials. Ceramic floor tiles generally have a triaxial composition consisting of clay, flux and filler. Fired bodies contain these 3 main component properties in the microstructure. In relation to the raw material composition (clay, quartz and feldspar), floor ceramic tile is considered to be a triaxial material. However, floor tiles are produced using a fast firing schedule. Different chemical and physical phenomena develop in this stage, this improves the composition and structure of the ceramic mass. Dissociation reactions of the clay minerals, physical and chemical water loss, formation of the new phases such as metakaolin and mullite carry out during firing. Considering floor tiles are generally fired in roller kilns, tiles are moving along the kiln carried by the rollers. It is possible that tiles can be bended by the roller movement because it is submitted to vertical forces due to its own weight. Since floor ceramic tiles densify via viscous phase sintering mechanism, viscosity of the liquid phase plays a critical role on microstructure development and hence stain resistance characteristics. While too high viscosity is not desired due to very slow densification kinetics, too low viscosity may also bring some additional problems such as increasing closed porosity and/or pyroplastic deformation. Therefore, viscosity should be monitored as a function of compositional modifications to interpret effect of composition design on microstructure and properties of floor ceramic tiles. Consequently, the research objective of this study were first to develop an understanding about how viscosity of floor tile changes as a function of alkali ratio $\left(\mathrm{Na}_{2} \mathrm{O} / \mathrm{K}_{2} \mathrm{O}\right)$ in a standard floor tile composition.

\section{Experimental procedure}

In this study, floor tile body composition was prepared by using industrial raw materials. A formulation, used for the industrial production of floor tiles, was chosen as a standard body mix. Starting from the standard body composition, different amounts of sodium and potassium feldispathic sands were added into the system. The new compositions were denoted as YK-STD, YK-6, YK-20. The Seger formulation was applied to prepare new compositions and $\mathrm{Na}_{2} \mathrm{O} / \mathrm{K}_{2} \mathrm{O}$ molar ratio was chosen as the main variable parameter to prepare the compositions and amount of total molar alkali oxides $\left(\mathrm{Na}_{2} \mathrm{O}\right.$ and $\left.\mathrm{K}_{2} \mathrm{O}\right)$ was kept constant in the compositions. Chemical analyses of the compositions are shown in Table I.

\section{TABLE I}

Chemical composition (wt\%) and $\mathrm{Na}_{2} \mathrm{O} / \mathrm{K}_{2} \mathrm{O}$ ratio (molar\%) of the recipes.

\begin{tabular}{c|c|c|c}
\hline \hline Compositions & YK-STD & YK-6 & YK-20 \\
\hline $\mathrm{SiO}_{2}$ & $71.633 \pm 2.0$ & $73.053 \pm 2.0$ & $71.7 \pm 2.0$ \\
$\mathrm{Al}_{2} \mathrm{O}_{3}$ & $21.01 \pm 1.0$ & $21.21 \pm 1.0$ & $20.94 \pm 1.0$ \\
$\mathrm{Fe}_{2} \mathrm{O}_{3}$ & $1.33 \pm 0.01$ & $1.21 \pm 0.01$ & $1.22 \pm 0.01$ \\
$\mathrm{TiO}_{2}$ & $0.67 \pm 0.01$ & $0.65 \pm 0.01$ & $0.64 \pm 0.01$ \\
$\mathrm{CaO}$ & $1.10 \pm 1.0$ & $1.053 \pm 1.0$ & $1.125 \pm 1.0$ \\
$\mathrm{MgO}$ & $2.21 \pm 2.0$ & $1.41 \pm 2.0$ & $2.19 \pm 2.0$ \\
$\mathrm{Na}_{2} \mathrm{O}$ & $4.70 \pm 0.2$ & $5.1 \pm 0.2$ & $5.27 \pm 0.2$ \\
$\mathrm{~K}_{2} \mathrm{O}$ & $1.58 \pm 0.2$ & $1.56 \pm 0.2$ & $1.42 \pm 0.2$ \\
$\mathrm{P}_{2} \mathrm{O}_{5}$ & $0.001 \pm 0.001$ & $0.002 \pm 0.001$ & $0.046 \pm 0.001$ \\
$\mathrm{Na}_{2} \mathrm{O} / \mathrm{K}_{2} \mathrm{O}$ & 4.511 & 4.963 & 5.643
\end{tabular}

New compositions were prepared by wet grinding. Slips were dried at $110^{\circ} \mathrm{C}$. The powders obtained were moisturised with $5 \mathrm{wt} \%$ water. The pellets with $50 \mathrm{~mm}$ diameter and $6 \mathrm{~mm}$ thickness were prepared by uniaxial pressing at a forming pressure of 44 bar (Nannetti Press, Hydraulic Laboratory Press Mignon S, Italy).

The determination of the pyroplastic deformation was carried out in the laboratory using Fleximeter hot stage 
microscope. Small bars of the floor tile bodies were prepared with a fixed length and thickness $(85$ and $8.5 \mathrm{~mm}$, respectively), which were subjected to thermal treatment, using the peak sintering temperature. Viscosity, water absorption and firing shrinkage values of the recipes were calculated according to Eqs. (1) and (2) for $1180^{\circ} \mathrm{C}$. For floor tiles deformation tests were carried out at $1185^{\circ} \mathrm{C}$ for $27^{\circ} \mathrm{C} / \mathrm{min}(4 \mathrm{~min}$ dwell time at peak temperature).

$$
P I=\frac{s b^{2}}{L^{4}},
$$

where $s$ - maximum deformation $(\mathrm{cm}), b$ - specimen's thickness $(\mathrm{cm}), L$ - distance between supports $(\mathrm{cm})$.

$$
V=\frac{\left(s \rho g L^{4}\right)}{32 s_{\max } b^{2}}
$$

where $\rho_{\mathrm{b}}$ - bulk density $\left(\mathrm{g} / \mathrm{cm}^{3}\right), g$ - gravity force $\left(\mathrm{cm} / \mathrm{s}^{2}\right), s_{\max }-$ maximum deformation velocity $(\mathrm{cm} / \mathrm{s})$, $V-$ viscosity.

\section{Results and discussions}

\subsection{Role of $\mathrm{Na}_{2} \mathrm{O} / \mathrm{K}_{2} \mathrm{O}$ ratio on viscosity of floor ceramic tile bodies}

Figure 1 shows the effect of $\mathrm{Na}_{2} \mathrm{O} / \mathrm{K}_{2} \mathrm{O}$ ratio on viscosity of the ceramic floor tile bodies. As the ratio increases, the viscosity decreases for all recipes, while the viscosity of the YK-STD composition with $4.511 \mathrm{Na}_{2} \mathrm{O} / \mathrm{K}_{2} \mathrm{O}$ ratio is $0.52 \mathrm{GPa}$ s. The change in the viscosity decreases

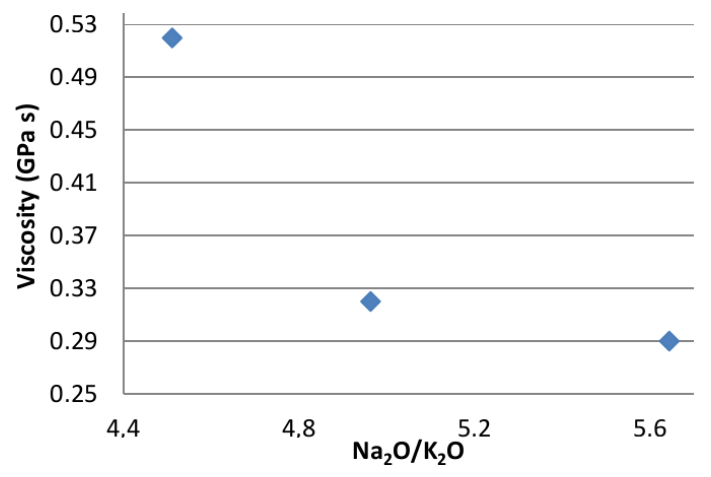

Fig. 1. Effect of the $\mathrm{Na}_{2} \mathrm{O} / \mathrm{K}_{2} \mathrm{O}$ ratio on the viscosity of the porcelain stoneware tile at $1185^{\circ} \mathrm{C}$.

as a function of the ratio at above $4.8 \mathrm{Na}_{2} \mathrm{O} / \mathrm{K}_{2} \mathrm{O}$ ratio for floor tile bodies. The reduction in the viscosity as a function of increase in the alkali ratio can be attributed to the network modifying characteristics of $\mathrm{Na}_{2} \mathrm{O}$ and $\mathrm{K}_{2} \mathrm{O}$. Network modifiers provide extra oxygen ions and these ions do not participate in the main network. This extra oxygen allows the bridging oxygen between 2 tetrahedra to be distrupted and 2 nonbridging oxygen to terminate each tetrahedron. These modifiers decrease the $\mathrm{SiO}_{4}$ interconnectivity. Therefore, decreasing viscosity of the recipes depending on the $\mathrm{Na}_{2} \mathrm{O} / \mathrm{K}_{2} \mathrm{O}$ ratio related to this loss of connectivity of the ions. In addition, technical properties of the recipes are represented in Table II.
TABLE II

Chemical composition (wt\%) and $\mathrm{Na}_{2} \mathrm{O} / \mathrm{K}_{2} \mathrm{O}$ ratio (molar\%) of the recipes.

\begin{tabular}{l|c|c|c}
\hline \multicolumn{1}{c|}{ Properties } & YK-STD & YK-6 & YK-20 \\
\hline viscosity values & $0.52 \mathrm{GPa} \mathrm{s}$ & $0.31 \mathrm{GPa} \mathrm{s}$ & $0.29 \mathrm{GPa} \mathrm{s}$ \\
firing shrinkage [\%] & 6.84 & 7 & 6.9 \\
water absorption [wt\%] & 2.27 & 2.10 & 2.0
\end{tabular}

\subsection{Role of $\mathrm{Na}_{2} \mathrm{O} / \mathrm{K}_{2} \mathrm{O}$ ratio on the pyroplastic deformation of the ceramic floor tile bodies}

The results of the comparative analyses of the samples subjected to a deformation cycle with Fleximeter are represented in Fig. 2. Starting point of the deformation for YK-6 is $980^{\circ} \mathrm{C}$, for YK-STD is $1050^{\circ} \mathrm{C}$ and for YK-20 is approximately $1125^{\circ} \mathrm{C}$. Therefore the best deformation result was obtained with the body corresponding to YK-20 recipe in which a kaolinitic clay was introduced at the expense of the sodium flux. Although the lower viscosity results show the highest starting deformation, excess viscosity decrease (i.e., too low viscosity) can bring additional problems such as pyroplastic deformation of the tiles. Therefore, there should be also a lower limit for the viscosity below which the tile exhibits pyroplastic deformation. To determine the lower viscosity limit for the studied system, the samples' shape will be analyzed whether there is any distortion or not after sintering.

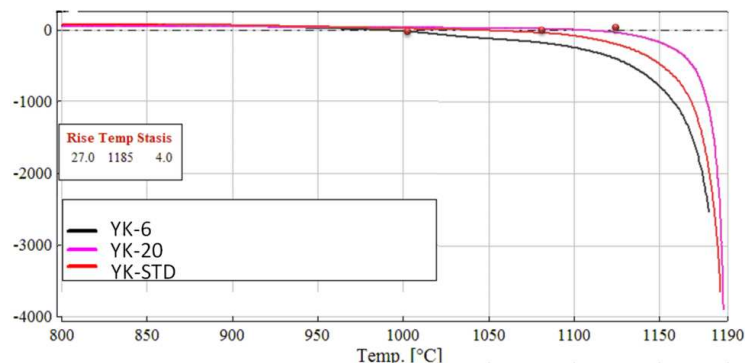

Fig. 2. Deformation behavior of the YK-STD, YK-6, and YK-20 compositions.

\section{References}

[1] E. Sanchez, M.J. Ibanez, J. Garcia-Ten, M.F. Quereda, I.M. Hutchings, Y.M. Xu, J. Eur. Ceram. Soc. 26, 2533 (2006)

[2] L. Esposito, A. Tucci, D. Naldi, J. Eur. Ceram. Soc. 25, 1487 (2005).

[3] M. Dondi, G. Ercolani, G. Guarini, C. Melandri, M. Raimondo, E.R. Almendra, P.M. Cavalante, J. Eur. Ceram. Soc. 25, 357 (2005).

[4] A.D.N. Junior, D. Hotza, V.C. Soler, E.S. Vilches, Mater. Sci. Eng. A 527, 1736 (2010)

[5] L. Esposito, A. Salem, A. Tucci, A. Gualtieri, S.H. Jazayeri, Ceram. Int. 31, 233 (2005)

[6] Y.M. Chiang, D.P. Birnie, D.W. Kingery, Physical Ceramics: Principles for Ceramic Science and Engineering, Wiley, New York 1996. 